\title{
Bio Insecticidal Activity of Soil Fungi against Grasshopper
}

\author{
A Reniprabha ${ }^{1 *}$ D Chitra ${ }^{2}$ and A Chandrakala ${ }^{1}$ \\ ${ }^{1}$ Department of zoology, India \\ ${ }^{2}$ Department of Zoology, India \\ *Corresponding author: A Reniprabha, PG and Research Department of zoology, Tamil Nadu

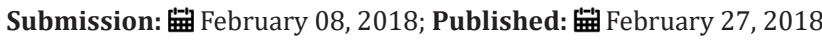

\begin{abstract}
The present study was undertaken to analyse the bio-insecticidal activity of various extracts of fungal isolates from the composite soil samples against grasshopper as test species. The fungal compound from the isolates was prepared using various extracts and the efficacy of insecticidal activity was assessed at different concentrations and at different intervals. It was found that the grasshoppers were effectively killed. Among the extracts, methanol extract of the fungal isolates was very active at 72 hours of exposure and the dosage of $50 \mu$ l concentration was found to be effective with high insecticidal activity.
\end{abstract}

Keywords : Bio-insecticide; Soil fungi; Grasshopper

\section{Introduction}

Majority of fungi were reported to produce many bioactive compounds. The antimicrobial and insecticidal properties of these compounds made to focus on the soil fungi to derive new bioactive compounds [1]. The dominant and common fungal species like As per gillus and Penicillium in soil paves way for the discovery of insecticidal compounds which will be a cheap source of biological compound in the production and utilisation of bioactive insecticides [2]. Thus the insecticidal potential present in soil borne fungi was investigated in the current study to assess its toxic potential as insect control agent against Grasshopper. Pesticides are applied in agriculture system for protecting crops from damage by insects. Moreover, continuous use of pesticides disrupts the natural balances [3]. So there is a need for an effective and environmental friendly method for controlling the pests $[4,5]$. Thus searching for new microbial agent to control pests becomes one of the most pressing needs.

\section{Materials and Methods}

\section{Sample collection}

Samples were collected from various crop fields (Paddy, Turmeric, Maize, Sugarcane, Tapioca and Banana of Erode District at five sites, viz., Bhavani, Komarapalayam,Thindal,Poondurai and Modakurichi. The samples were collected during the period from July 2014 to May 2015 from different places in the same field at $15 \mathrm{~cm}$ depth randomly and pooled together. It was processed to remove lumps and debris and stored in a small sterilized polythene bags and brought to the laboratory for further studies. Three replicates of composite soil samples were made [6]. One composite samples was prepared by mixing of minimum of 10 soil cores on a same area $\left(10 \mathrm{~m}^{2}\right)$. The collected soil sample bags were labelled properly showing the site of collection. The samples were sieved and air dried for 3-5 days at18 0c. After drying, samples were kept at100c until used [7].

\section{Soil dilution plate method}

Soil was diluted by dissolving $1 \mathrm{~g}$ of soil of each sample in $10 \mathrm{ml}$ of sterile distilled water. Dilutions of 10 -3 10-4 and 10-5 were used to isolate fungi in order to avoid over-crowding of the fungal colonies. One ml of the suspension of each concentration was taken in Petri plates, in triplicates of each dilution, containing Fungal Agar medium and to prevent bacterial contamination $1 \%$ streptomycin was added before pouring into Petri plates. The plates were then incubated at 28+2 0C for 4-7 days. Organisms were easily isolated because they formed surface colonies that were well dispersed particularly in higher dilutions [8,9].

\section{Identification of the soil fungi}

The fungal species were identified by observing the morphological characteristics of the colony and microscopic examinations (5). The length and width of the colony, the presence or absence of aerial mycelium, the color, wrinkles, furrows and pigmentation were the macro morphological characters helped to identify the species following standard procedure and relevant literature $[7,10]$. 


\section{Extraction of secondary metabolites from pure isolate}

After incubation the broths were filtered through Whatmann No. 1 filter paper and then through $0.45 \mathrm{~mm}$ Millipore (Millipore Millex -HV Hydrophilic PV). The filtrate was transferred aseptically into a conical flask and stored at $4 \mathrm{C}$ for further assay. To the culture filtrate, equal volume of ethyl acetate was added and shaken well in separating funnel. The organic layer was separated and dried. The dried solid residue was redissolved in Methanol [11].

\section{Screening of insecticidal activity producing fungal isolates}

The insecticidal activity of the fungal extract the insects was determined by fumigant bioassay using the closed container method. A group of 10 insects were put into the bottom of a
$40 \mathrm{ml}$ the plastic container .Paper discs were treated with $100 \mathrm{mg}$ concentrations of extracts.

\section{Results and Discussion}

Different crop fields were selected for sampling like paddy , sugarcane, turmeric, maize, tapioca, banana and organic field from five locations denoted as site 1(Bhavani),site II(Komarapalayam) site III(Thindal),site IV(Poondurai) and site V(Modakurichi) which are the major agricultural areas of Erode Taluk. As shown in Table 1, majority of soil samples were taken from paddy fields (43) and sugarcane fields (17) followed by banana fields (10), maize fields (19), turmeric fields, tapioca and organic fields (6). Similarly maximum number of soil samples were collected from Bhavani area (36) and Modakurichi (22) where agriculture lands are more.

Table 1: Collection of soil samples from different crop fields of Erode Taluk.

\begin{tabular}{|c|c|c|c|c|c|c|c|c|}
\hline Fields & Paddy & Sugarcane & Turmeric & Maize & Tapioca & Banana & $\begin{array}{c}\text { Organic } \\
\text { Fields }\end{array}$ & $\begin{array}{c}\text { Total } \\
\text { Others }\end{array}$ \\
\hline Bhavani & 10 & 11 & 4 & 3 & 3 & 2 & 1 & 2 \\
\hline Komarapalayam & 8 & 2 & - & - & - & 1 & 1 & 13 \\
\hline Thindal & 6 & - & - & 3 & - & 2 & 1 & 12 \\
\hline Poondurai & 10 & 1 & - & 1 & - & 2 & 2 & 1 \\
\hline ModaKurichi & 9 & $3 z$ & 2 & 2 & - & 3 & 1 & 1 \\
\hline Total & 43 & 17 & 6 & 9 & 6 & 10 & 6 & 5 \\
\hline
\end{tabular}

Table 2: Observation of the insecticidal activity of fungal compound in Methanol extract against Grasshopper.

\begin{tabular}{|c|c|c|c|c|c|c|c|c|c|}
\hline \multirow{2}{*}{$\begin{array}{c}\text { ISO } \\
\text { NO }\end{array}$} & \multicolumn{3}{|c|}{$30 \mu \mathrm{r}$} & \multicolumn{3}{c|}{$40 \mu \mathrm{c}$} & \multicolumn{3}{c|}{$50 \mu \mathrm{c}$} \\
\cline { 2 - 10 } & \multicolumn{3}{|c|}{ Hours } & \multicolumn{3}{c|}{ Hours } & \multicolumn{3}{c|}{ Hours } \\
\cline { 2 - 11 } & 24 & 48 & 72 & 24 & 48 & 72 & 24 & 48 & 72 \\
\hline 1 & - & - & + & + & - & - & - & + & - \\
\hline 2 & - & - & - & + & - & - & - & + & - \\
\hline 3 & - & - & - & - & + & - & + & - & + \\
\hline 4 & - & - & - & - & - & - & - & - & + \\
\hline 5 & - & - & - & - & - & + & - & - & + \\
\hline 6 & - & - & - & - & - & - & + & - & + \\
\hline 7 & - & - & - & - & - & + & + & - & + \\
\hline 8 & - & - & - & - & - & - & - & + & + \\
\hline 9 & - & - & - & + & - & - & - & + & + \\
\hline 10 & - & - & - & - & - & - & + & - & + \\
\hline
\end{tabular}

Table 3: Observation of the insecticidal activity of fungal compound in Ethylacetate extract against Grasshopper.

\begin{tabular}{|c|c|c|c|c|c|c|c|c|c|}
\hline \multirow{2}{*}{$\begin{array}{c}\text { ISO } \\
\text { NO }\end{array}$} & \multicolumn{3}{|c|}{$30 \mu \mathrm{I}$} & \multicolumn{3}{c|}{$\mathbf{4 0 \mu l}$} & \multicolumn{3}{c|}{$50 \mu l$} \\
\cline { 2 - 10 } & 24 & 48 & 72 & 24 & 48 & 72 & 24 & 48 & 72 \\
\hline \multirow{2}{*}{1} & - & - & + & + & - & - & - & + & - \\
\hline 2 & - & - & - & + & - & - & - & + & - \\
\hline 3 & - & - & - & - & + & - & + & - & + \\
\hline 4 & - & - & - & - & - & - & - & - & + \\
\hline 5 & - & - & - & - & - & + & + & + & + \\
\hline 6 & - & - & - & - & - & - & + & - & + \\
\hline 7 & - & - & - & - & - & + & + & - & + \\
\hline 8 & - & - & - & - & - & - & - & + & + \\
\hline 9 & - & - & - & + & - & - & - & + & + \\
\hline 10 & - & - & - & - & - & - & + & - & + \\
\hline
\end{tabular}


From the present investigation, it was observed that the extract from the soil fungi was found to be active against the selected pest grasshopper, Tables 2-4 showed that the methanol extract of 10 isolates killed grasshopper effectively at $50 \mu \mathrm{l}$ concentration when compared to ethyl acetate and butanol extracts. But the duration effectiveness was long ( $72 \mathrm{hrs}$ ) in $50 \mu \mathrm{l}$ concentration. Ethylacetate extract was found to be effective at higher concentration $(50 \mu \mathrm{l})$ and at long duration (72hrs). Thus the bioactive compound effect was dose and duration dependent.

Table 4: Observation of the insecticidal activity of fungal compound in Butanal extract against Grasshopper.

\begin{tabular}{|c|c|c|c|c|c|c|c|c|c|}
\hline \multirow{2}{*}{ ISO } & \multicolumn{3}{|c|}{$30 \mu \mathrm{l}$} & \multicolumn{3}{c|}{$40 \mu \mathrm{l}$} & \multicolumn{3}{c|}{$50 \mu \mathrm{I}$} \\
\cline { 2 - 10 } NO & \multicolumn{3}{|c|}{ Hours } & \multicolumn{3}{c|}{ Hours } & \multicolumn{3}{c|}{ Hours } \\
\cline { 2 - 10 } & 24 & 48 & 72 & 24 & 48 & 72 & 24 & 48 & 72 \\
\hline 1 & - & - & + & + & - & - & + & + & - \\
\hline 2 & - & - & - & + & - & - & - & + & - \\
\hline 3 & - & - & - & - & + & - & + & - & + \\
\hline 4 & - & - & - & - & - & - & - & + & + \\
\hline 5 & - & - & - & - & - & + & - & + & + \\
\hline 6 & - & - & - & - & - & - & + & - & + \\
\hline 7 & - & - & - & - & - & + & + & + & + \\
\hline 8 & - & - & - & - & - & - & - & + & - \\
\hline 9 & - & - & - & + & - & - & - & + & - \\
\hline 10 & - & - & - & - & - & - & + & - & + \\
\hline
\end{tabular}

From the above results, the sequence of effectiveness of fungal extract against the grasshopper was methanol $>$ ethyl acetate $>$ butanol. Thus, the methanol extract of fungal isolate was found to be active in causing mortality of grasshopper. Similar observations have been made by many authors who reported that fungi could be used as an effective biological compound to control pests because of the secondary metabolite produced by fungi was harmful to the pests. The exact mode of toxic action was not determined in the present work. The As per gillus was found to possess the harmful toxic metabolite which cause acute and chronic toxicological effect an insects and man .A sudden increase in mortality of Japanese beetle Papillia japonica was noted when the adult beetles were treated with the fungal extracts of Metarrhizium anisopliae and Beauveria bassiana. The insects were controlled by the bioactive compound from fungi and it has been a very active area of research $[2,6,5]$. Fungi could be effectively used as bio control agents because of their ability to actively infect and kill the target pest [8]. The fungi were found to be effective against insects including locusts, grasshopper, mosquitoes and other [1]. Commercial biological control including fungi is a hitech venture in terms of Safety and sustenance.

\section{Conclusion}

The research on identification of bioactive compounds from soil fungal isolates is receiving much attention due to is environmental and food safety concerns and the negative impact of chemical pesticides as well as emergence of number of insecticide resistant species. Hence this type of research will be of very useful.

\section{Acknowledgement}

We would like to thank our Institution of Chikkaiah Naciker College, Erode for providing the necessary facilities for this study.

\section{References}

1 Achonduh OA, Tondje PR (2008) First report of pathogenicity of Beauveria bassiana RBL1034 to the malaria vector, Anopheles gambiens (Diptera; Culicidae) in Cameroon. African Journal of Biotechnology 7(8): 931-935.

2 Butt TM, Jackson CW, Magan N (2001) Fungal biological control agents: Progress, Problems and Potential. CABI International, Walling ford, Oxon, UK.

3 Dowd PF, Peng FC, Chen JW, Lingka (1992) Toxicity and, anticholinesterase activity of the fungal metabolites terri trems to the corn earworm, Helicoverpa zea. Entomol Exp Appl 65(1): 57-64.

4 Fravel DR (2005) Commercialization and implementation of biocontrol. Ann Rev Phytopathol 43: 337-359.

5 Gilman JCA (2001) Manual of soil fungi. In: (2 $2^{\text {nd }}$ edn), Biotech Books, Delhi, India.

6 Jackson MA, Dunlop CA, Jaronski ST (2010) Ecological consideration in producing and formulating fungal entomopathogens for use in insect biocontrol. Bio Control 55(1): 129-145.

7 Lacey LA, Martins A, Riberiro C (1994) The pathogenicity of Metarrhizium anisopliae and Beauveria bassiana for adults of the Japenese beetle, Papillia japonica. Env J Entomol 91(3): 313-319.

8 Nagamani A, Kumar IK, Manoharachary C (2006) Hand book of soil Fungi. IK International Publishing House Pvt Ltd, New Delhi, India.

9 ShiWB, Feng MG (2004) Lethal effect of Beauveria bassiana, Metarhizium anisopliae, and Paecilomyces fumosoroseus on the eggs of Tetranychus cinnabarinus (Acari: Tetranychidae) with a description of mite egg bio assay system. Biological Control 30(2): 165-173.

10 Waksman SAA (1922) Method for counting the number of fungi in the soil. J Bactol 7(3): 339-341.

11 Whitten MJ, Oakeshott JG (1990) Biocontrol of Insects and Weeds. In Agricultural and Biotechnology. In: Gabrielle JP [Ed.], CAB International, London, pp. 305.

12 Zahner H, Ankle H, Ankle T (1983) Evolution and secondary pathways. In: Secondary Metabolism and Differentiation in fungi. In: Benett JW, Ciegler A, Marcel Bekker [Eds.], New York, USA, pp. 153-175. 
(c) (i) Creative Commons Attribution 4.0 International License

For possible submissions Click Here

Submit Article
Your subsequent submission with Crimson Publishers will attain the below benefits

- High-level peer review and editorial services

- Freely accessible online immediately upon publication

- Authors retain the copyright to their work

- Licensing it under a Creative Commons license

- Visibility through different online platforms

- Global attainment for your research

- Article availability in different formats (Pdf, E-pub, Full Text)

- Endless customer service

- Reasonable Membership services

- Reprints availability upon request

- One step article tracking system 